Delft University of Technology

\title{
Co-creating Responsible Energy Systems
}

Hunink, Yvo Thomas Anton; Kamp, Linda Manon; Blom, Esther Maria

DOI

10.1007/978-981-32-9119-5_28

Publication date

2020

Document Version

Final published version

Published in

ISGW 2018 Compendium of Technical Papers - 4th International Conference and Exhibition on Smart Grids and Smart Cities

\section{Citation (APA)}

Hunink, Y. T. A., Kamp, L. M., \& Blom, E. M. (2020). Co-creating Responsible Energy Systems. In R. K.

Pillai, S. Chaudhuri, G. Ghatikar, R. Seethapathy, V. L. Sonavane, S. A. Khaparde, \& P. K. Yemula (Eds.), ISGW 2018 Compendium of Technical Papers - 4th International Conference and Exhibition on Smart Grids and Smart Cities (pp. 329-342). (Lecture Notes in Electrical Engineering; Vol. 580). Springer.

https://doi.org/10.1007/978-981-32-9119-5_28

Important note

To cite this publication, please use the final published version (if applicable).

Please check the document version above.

\footnotetext{
Copyright

Other than for strictly personal use, it is not permitted to download, forward or distribute the text or part of it, without the consent of the author(s) and/or copyright holder(s), unless the work is under an open content license such as Creative Commons.

Takedown policy

Please contact us and provide details if you believe this document breaches copyrights.

We will remove access to the work immediately and investigate your claim.
} 
Green Open Access added to TU Delft Institutional Repository 'You share, we take care!' - Taverne project

\section{https://www.openaccess.nl/en/you-share-we-take-care}

Otherwise as indicated in the copyright section: the publisher is the copyright holder of this work and the author uses the Dutch legislation to make this work public. 


\title{
Co-creating Responsible Energy Systems
}

\author{
Yvo Thomas Anton Hunink, Linda Manon Kamp \\ and Esther Maria Blom
}

\begin{abstract}
Energy system projects in countries like India are often failing. Not only because of technical or economical barriers, but mainly institutional and social issues are at the base of these failures. A co-creation, or participatory, process to align all demands and requirements of the different stakeholders is required. This paper takes evidence from literature on co-creation and energy systems and from case study research in India to help define an approach towards such a co-creation process as a use case for the application of the Responsible Innovation Systems framework. A discussion on co-creation as a solution generates a number of recommendations, after which a set of characteristics is concluded that the co-creation process of energy systems should have towards a responsible approach, so that more robust and sustainable innovations might emerge.
\end{abstract}

Keywords Co-creation - Participatory process $\cdot$ Responsible innovation systems • Energy systems - Sustainable innovation - Process design

\section{Introduction}

Worldwide, 1.1 billion people lack access to electricity, of which 276 million are located in India [11]. Kerosene and firewood are among the most used alternatives for energy and can pose serious health threats [3]. The introduction of decentralized

\footnotetext{
Y. T. A. Hunink ( $\square)$

Responsible Innovation, Energy Bazaar, The Hague, The Netherlands

e-mail: yvo@energybazaar.org

L. M. Kamp

Faculty Technology, Policy and Management, Delft University of Technology, Delft,

The Netherlands

e-mail: 1.m.kamp@tudelft.nl

E. M. Blom

Delft Centre for Entrepreneurship, Delft University of Technology, Delft, The Netherlands

e-mail: e.m.blom@tudelft.nl

R. K. Pillai et al. (eds.), ISGW 2018 Compendium of Technical Papers,

Lecture Notes in Electrical Engineering 580,

https://doi.org/10.1007/978-981-32-9119-5_28
} 
energy resources, such as solar panels, provides a new set of opportunities to improve these numbers and alleviate millions from energy poverty. However, numerous examples are known where energy projects were:

- Not accepted by the communities [17]

- Not providing the necessary improvements in people's lives [7]

- Endangered by expansion of the subsidised, and fossil fuel-based, central public grid [5].

The most apparent reason for failures of energy systems seems to be that the many stakeholders involved in the innovation system, are not sufficiently aligned towards a consensus on how to form the projects. It has become apparent that there are significant influences of social and cultural values involved with energy exchange [19], which are often not accounted for. It stresses that a purely economic model for energy systems does not take into account the demands of a community. Additionally, the research by Comello et al. [5] shows that problems in energy system adoption not only originate from the local level, but also arise from institutional barriers, that can only be solved by policy makers. Also, there are many technologies being proposed for use in energy systems, such as blockchain and artificial intelligence, which are still subject to extensive research and implementation barriers, requiring decision-making activities in both industries and universities.

The main challenge of this research, therefore, is to determine a set of characteristics for a collective innovation process of energy systems, where all these actors are included, shared objectives can be determined, role divisions instigated and collective resources created, so that the activities can be aligned, innovations are more likely accepted and the rate of electrification in the world might go up. The terms co-creation and participatory programs are often found to describe such processes.

\section{Methodology}

A literature study will expose what is currently known about co-creation, both in the context of India and in relation to energy systems. Thereafter, a relevant theoretical approach is presented that could guide a co-creation process.

A number of field visits to the rural parts of India are used to generate insights on the co-creation processes of energy technologies for these areas. A total of five projects by different organizations with different products are visited and examined on characteristics of the co-creation process in the perspective of the approach explained in the literature study, being:

- Smart meters, Bhodgaya (Bihar), Gram Power

- Solar home systems, Bankey Bazar (Bihar), Rural Spark 
- Solar home systems, Badaun (Uttar Pradesh), Rural Spark \& Simpa Networks

- Solar irrigation, Daulatpur (Bihar), Claro Energy

- Community microgrid, Buknari (Bihar), Vayam Renewable.

Lastly, a synthesis of the findings is made towards a set of objectives for a co-creation process of energy systems for the context of India.

\section{Literature Study}

In this section, an overview is given on available research on co-creation processes in India (3.1), co-creation in energy systems (3.2) and the Responsible Innovation Systems approach (3.3).

\subsection{Co-creation in India}

Across several sectors, participatory programs are found in India. In agriculture, for example, farmer participation in crop variety introduction has proven to successfully increase crop diversity [12]. However, a randomized evaluation on participatory education intervention programs in India sketches a different image. It was exposed that the results of such programs depend on the details of the intervention and the contexts [1]. Three interventions were researched. The results of the interventions, based on the tested level of education of the children, show that the two interventions that were mainly information-based, had negligible effect. The third approach, however, which gave a specific action-based tool, showed significant improvement. Therefore, participatory programs appear more likely to be successful if a clear action plan is provided for participants.

The demand for participatory rural energy planning in India has resulted in a new model for stakeholder's roles, visible in Fig. 1 in the Appendix (Neudoerffer 2001). While since then a slow uptake of energy cooperatives has taken place, such initiatives appear to have helped in reducing distribution losses and electricity theft in India, while also improving billing and revenue collection efficiency [14]. However, while participatory and cooperative initiatives on energy systems in India exist, no exhaustive empirical research could be found to draw extensive conclusions on a best-practice approach, making it valuable to explore other contexts of co-creation in energy systems. 


\subsection{Co-creation in Energy Systems}

Already in 2003, it was found that renewable energy cooperatives in Bangladesh could form the foundation for sustainable rural development, by targeting economic, environmental and community development through the village level supply of energy [18]. A historical example from Canada, however, shows that the successful electrification of the country spanned a period of over 50 years and demanded the active involvement of rural farmers, grouped into cooperatives [20].

Since then, extensive research has been done which has shown that community investment and ownership in energy projects can have far reaching positive impact, but also experiences significant barriers, especially economically and socially $[8$, 22]. Additionally, a comparative case study of Western energy cooperatives finds that the evolving institutional configuration of an energy sector is a significant factor in the development of community initiatives, where it can both limit and enable community energy projects depending on the configuration [13]. Decentralization of the institutional space and alignment of discourses between stakeholders generally appears to increase the chances for local community players.

In an attempt to create a conceptual framework for understanding the introduction of renewable energy infrastructure in society [23] propose to take a broad perspective, looking at political, market and societal and community acceptance. Devine-Wright et al. [6] later suggest that each of those three need to be expanded and segmented in levels of international, national and local influence and the role of 'middle' actors. Middle actors influence the system both bottom-up, top-down and sideways and often across institutional boundaries [15].

Koirala et al. (2016) take a next step in defining a framework for cooperation in energy systems. After a comparative analysis of different approaches of cooperative energy solutions, they propose the Integrated Community Energy System (ICES), combining the concepts of sustainable energy communities, community energy systems, community microgrids, and peer-to-peer energy. Figure 2 in the Appendix shows what such a system would entail. Central to the ICES is the creation of a local energy market, which would allow solar panel owners to exchange their energy and create notable extra revenues, increasing the attractiveness of buying solar panels instead of traditional grid connection. The ICES model, therefore, appears to be a good foundation that would improve the chances of local adoption of technologies, by creating local energy markets. Still, ICESs are also found to face key barriers in technological, socio-economic, environmental and institutional issues.

It appears that the same barriers keep on returning, but not a single one-size-fits-all solution can be appointed for mitigating such barriers. In complex innovation systems, with many different stakeholders, it can be expected that each situation with different contextual characteristics requires a custom-made process of aligning the activities. This is why a more holistic view needs to be taken. 


\subsection{Responsible Innovation Systems}

A new approach towards guiding collective innovation processes is the Responsible Innovation Systems framework, which can help to align stakeholders in an evolving innovation system to come to more responsible and sustainable collective solutions [10]. The framework was tested in the rural energy technology innovation system in India, showing that it can be relevant for this case. The framework is a synthesis of other innovation approaches and consists of 3 elements, the components, relations and functions, which is presented in Fig. 3 of the Appendix.

The components element is composed with the Quadruple Helix [2], which categorizes relevant stakeholders in the four institutions of government, academia, industry and the culture- and media-based public (or civil society). Each institution, defined as a rule-based societal structure and selection mechanism for decision making in innovation processes, is required to be included in the collective innovation process, so that alignment of activities might happen. Each of the institutions creates a specific type of knowledge, respectively, political, human, economic and social 'capital'. The evolutionary characteristic is expressed in the notion that actors can also take over roles of other institutions and create multiple types of capital, effectively creating multi-institutional organizations, which often act as the 'middle' actors explained in Sect. 3.1.

The relations element uses the approach of Open Innovation [4], to describe the knowledge channels within the innovation system and argues that these should be as open as possible, creating two-way communication patterns between actors. It results in a free flow of the different capitals across the institutional boundaries, evidently needed for alignment of activities.

The functions element is largely derived from research by Ranga and Etzkowitz [16], which defined three virtual spaces that are required in a functioning innovation system, namely those of Knowledge, Innovation and Consensus, of which the latter is extended with the Responsible Innovation approach [21]. The Knowledge Space is formed when knowledge is created or shared between actors. The Innovation Space is formed when this knowledge is combined into new products, services or processes. The Consensus Space is formed when the 'dimensions' of Responsible Innovation [21] are found in the activities of actors and their partners. The dimensions can be used to filter innovation processes that might lead to 'collective irresponsibility and are defined as:

- Anticipation-Determining future visions, risks, effects, opportunities and situations. Asking the question'What if..?' and setting goals and targets.

- Reflexivity - A retrospective view on one's own role and those of others, by holding a mirror up to the activities, commitments and assumptions and how this affects others in society. 
- Inclusion-Participation of all relevant stakeholders that might influence innovation and are influenced by innovation, in the several phases of the process.

- Responsiveness-A capacity to change shape or direction in reaction to changing circumstances.

Only if all dimensions, of which inclusion is already embodied in the components elements, are enhanced in the activities of actors in the system and mutually shared among them, the Consensus Space will form and a responsible collective innovation process is in place. A broad intake of these dimensions is taken, allowing all forms of enhancement to be relevant. Also the dimensions are intertwined and can be in tension with each other, both positively as negatively.

Because the framework was taken to rural India for an initial case study, it has touched upon activities in practice. However, it has not fully left the academic sphere, since it has not yet been used to actually design a collective innovation process and it is subject to a number of recommendations for improvement. Still, a co-creation process as proposed for microgrid design, appears to already be a suitable initial use case to apply the Responsible Innovation Systems framework to, because the process would lend itself for constant iteration of insights along the process.

\section{Observations from Fields Visits}

In this section, the most notable findings during the field visits are presented. While the interviews described were also used in the original research that instigated the Responsible Innovation Systems framework and a full analysis following the different elements should be sought in the work of Hunink et al. [10], this section takes some observations from those visits that show how the framework can help expose relevant factors for a co-creation process of energy systems.

The smart meters in Bodhgaya, installed by a private DISCOM, had very little co-creation in them. The shop owner that was interviewed, just received this new meter one day. The smart meter had an interface that the shop owner could not access, because he did not possess a smart phone, preventing him from fully exploiting the possibilities of the smart meter platform, such as insights in consumption patterns, of which he was not even aware it existed. It shows that a lack of inclusion of the end user with the activities of the industry partners and closed communication channels, undermines the potential that these smart meters have and resulted in a lack of anticipation, reflexivity and responsiveness.

In the community microgrid, a completely different dynamic was observed. After an initiative of a village member to create a microgrid, 43 of the 200 households expressed their willingness and ability to be part of such a grid. Together with the company building the grid, a custom design was made, taking into account the specific wishes and demands of the community towards a strong Consensus Space. A clear role division was made (reflexivity), communication channels were kept open (inclusion) and an action plan was set up in case of calamities (responsiveness). Looking at the ICES model, explained in Sect. 3.2, this 
project showed clear community generation and energy management. At the time of interviewing, 1.5 years after installment, the villagers expressed their happiness with the system, the sense of ownership they had in the project and were even actively involved in further innovating the system. They were now trying to persuade the company to expand the system with a running water system powered by solar panels (anticipation and Innovation Space), also showing some human capital creation. Several elements, therefore, were clearly visible. A missing element was the role of the government, showing that this successful project could be vulnerable to changes in the political environment due to a lack of political capital.

The solar home systems in Badaun exposed how a disconnected government, can play a limiting role. While nearby villages had a connection to the central grid, this particular village was not connected. Upon asking why this was, the villagers explained that in the previous election they had voted for the losing party, which has damaged the connections they had to local government. It prevented them from being included in the electrification process and forced them to individually rely on solar home systems instead, preventing the local community from having collective reflexivity and responsiveness, leaving them only to anticipate on the future. With upcoming elections, as they expressed, they would vote for the party in favor of winning, so they would be connected to the grid this time. This would mean the continuity of using and expanding the solar home systems was not ensured, all because of the closed communication and limiting role of the government.

The solar irrigation plant in Daulatpur showed that effective inclusion of government, however, can help in creating a robust project. The irrigation department was explicitly involved with the design of the projects, together with the industry partner and a cooperative of farmers. The project was designed to run for five years and had all this time been going according to the plan that was set up with all those actors. The requirements of each involved institution were included and aligned, showing a strong Consensus Space. Additionally, the effect of inclusion on the other dimensions of Responsible Innovation became apparent. Initially the inclusion was high, resulting in clear role divisions (reflexivity), a 5-year plan (anticipation) and effective billing procedures organized by the farmer community themselves (responsiveness). At the point of interviewing, however, the 5-year contract was almost ending and the farmer was not being included in any conversations regarding the continuity, resulting in doubts about his role, the future and how to respond when the contract ends.

Finally, the solar home systems in Bankey Bazar revealed what the impact can be of taking over the role of human capital creation, originally being a responsibility of the academic institution. By internalizing the skill of entrepreneurship into the product, by adding a set of batteries that can be rented out, the users were found to create new competencies and generate additional income. This characteristic of the product was added after a co-creation process where they observed how people were using lamps and batteries they distributed amongst communities. It shows strong signs of the Knowledge and Innovation Spaces at work and has led to rapid iteration of the innovation process to better suit the needs of the end user, while also increasing the agency to come up with new solutions in using the product at their 
will. The Consensus Space was also visibly enhanced. The product increased the reflexivity of end users, by adopting a new role in their community of energy supplier, also creating social and economic capital. It enhanced anticipation, because the future changes to the product actively influenced their businesses. Ultimately their responsiveness increased by earning additional income and being able to structure their business model according to local situations. The ICES model is largely visible, since the community takes up generation, management and storage of energy, while also creating a local energy market.

\section{Discussion and Recommendations}

The observations during the field visits show that the projects that contained more elements of the Responsible Innovation Systems framework in their (co-creation) process, could be seen to harness the potential of the situation much better and generally create solutions that are easier adapted. The sense of ownership and willingness to expand on the existing infrastructure was increased, allowing a faster innovation process to take place, with a better chance of acceptance by the end user. While co-creation was seen to potentially have meaningful benefits, this does not automatically mean that co-creation or participation is a silver bullet, as the research by Banerjee et al. [1] showed in Sect. 3.1. Several things can be noted that might obstruct a smooth process

\subsection{Design of the Process}

An important part of the co-creation process is taking the time to get to know each other, so that the shared or conflicting values and requirements can be determined and better aligned and trust between the stakeholders can be established. However, the amount of time and resources spent can increase significantly and without results coming in, can actually reduce the responsiveness of actors. It should be recommended that a clear timeline and resource allocation is anticipated, so that negative consequences can be limited to a minimum. This does not mean that each phase and stage of the process should be designed up front and completely followed. A co-creation process rather is a complex set of activities in which each phase and stage is dependent on the previous. The complete co-creation process, therefore, is unclear at the beginning, but two key phases should always be there, in which all institutions are at least included.

First, an exploration should be used to carefully create the specific shared and conflicting demands of the stakeholders in the co-creation process. It will also help define the initial necessary contents of the process. Since it is of outmost importance to know the social and cultural dynamics within communities that participate in a co-creation process, a necessary stage within the exploration phase is the 
ethnographic study. Here the socio-cultural context should be revealed, where values and objectives of all the different stakeholders can be determined and the right strategy towards the process can be derived. For example [9] conclude that community projects are more likely to succeed when there is already a sense of community present. Conflicting interests within communities can seriously impede the co-creation process in relation to the developers building the energy system. Therefore, whenever such community sense is not there, the goal should be first to create this.

Secondly, a reflection phase must evaluate the process at the end, letting all actors come together and discuss relevant topics, keeping an open knowledge environment. In between these phases, the contextual characteristics of the project will determine what the rest of the process should look like. It should be evaluated whether separate stages are required and if varying involvement of stakeholders is needed. However, after each stage and phase, clear follow-up activities with an action plan should be formed, in line with [1], to ensure that each session is processed and shall be communicated to all the stakeholders, so that they can utilize the outcomes of the sessions to a maximum, also relating to responsiveness. Additionally, it is advised that the continuous design of the process remains subjected to academic research. Since it is new terrain that is explored, research questions should be set up that see to new insights on the constant monitoring and improvement of the process.

\subsection{Role of the Facilitator}

In the model from Neudoerffer (2001) in Fig. 1, each of the required institutions, according to the Responsible Innovation System, is already visible, however they are only indirectly in contact with each other. This leaves the possibility of demands and requirements of each actor to be missed, overruled or corrupted. In the projects with end users, it was impossible to retrieve the workings of this structure from the interviews done, with only the relation between villages and product manufacturers observed. The model appears static and does not allow for flexible approach towards the role division and the interaction between actors, questioning its usability.

The role of disseminator, or facilitator, is only between NGOs and government in the model. This role, however, could be expanded to act in the middle of all institutions, including industry and academic research institutes. This could be in the form of facilitating the joint co-creation sessions, or simply to take the role of a missing institution whenever decision making on innovations is happening. Therefore, this facilitator effectively becomes the 'middle' actor, as described in Sect. 3.1. It would instigate a different type of process, where the initial role 
divisions and interactions are not predetermined, but rather evolve from co-creation in an initial stage, as seen in Fig. 4. It would create a process that is able to uptake contextual influences much better and accordingly adjust.

The facilitator should be in the position to help design the process and ensure that the components of the Responsible Innovation Systems framework are included. It should organize the stakeholders, educate them about the importance of co-creation and sketch the path of the process. A large skillset on technical elements of energy systems and the Indian innovation system surrounding the development of the sector and its policies will help to fulfil such a task.

However, communicating with rural end users should always be done by someone that is trusted by the community and has the knowledge on specific socio-cultural contexts. Taking an active role in a co-creation setting with participants that do not trust the facilitator could be more harmful than helpful, due to misjudgment of nuances, and should therefore be minimized. A mediator should be present during the co-creation sessions who is respected and known to all stakeholders, but not feared in such a way that the openness of the conversation is endangered.

It is therefore that the facilitator should allows others to take a leading role during co-creation sessions in the different phases and stages, wherever the contextual characteristics require such. In such cases, the facilitator preferably also designs the session in cooperation with that actor. Similarly, to inclusion of end users, it will increase ownership of the process among all stakeholders. However, the exact role of the facilitator is not completely clear yet and should be subjected to further research.

\subsection{Local Energy Markets}

The ICES model (Koirala et al. 2016), explained in Sect. 3.2, is seen as the most integrated approach towards cooperative energy grids. However, the model was said to face key barriers in technological, socio-economic, environmental and institutional issues. The Responsible Innovation Framework is meant to prevent such barriers by determining the characteristics of a collective innovation process. From the field visits, it appeared that the projects with the most signs of the elements of the framework (Buknari and Badaun), were also the ones with visible parts of ICES model. It could be a hint that a co-creation process towards an ICES that applies the Responsible Innovation Systems framework has an enlarged change of success, because it mitigates the barriers for ICES adoption. It is recommended to explore such a combination. 


\section{Conclusion}

This research aimed to gain answers on what a co-creation process for the formation of energy systems in India should look like. After a literature study, several characteristics for co-creating energy systems in India were found and it was determined that the Responsible Innovation Systems framework poses as a suitable guidance for the design of a co-creation process with the help of a number of field visits. The characteristics for the co-creation process of energy systems are concluded to be the following:

- Inclusion of all four institutions of government, industry, academia and civil society from the local, national and international level.

- An open knowledge sharing environment.

- A multi-phase process with a clear timeline and resource allocation, always starting with an exploration phase and ending with a reflection phase in which all institutions are present, where each phase is dependent of the previous one and can have multiple stages.

- In the exploration phase, an ethnographic analysis of the community in which the energy system is introduced is required as a separate stage. Here, at least the sense of community within the selected group is determined.

- Knowledge production and sharing is enabled, while innovation of new products, services and processes is fostered.

- Activities for enhancement of anticipation, reflexivity and responsiveness are shared among the stakeholders of the process.

- Creation of a local energy market, following the ICES model, after which further integration in the energy system can take place.

- A flexible role for a facilitator to help design and guide the co-creation process, while also being able to step down from the leading role when the contextual circumstances require such.

- Create clear action plans for stakeholders after each stage and phase, to ensure further development.

- Ending in a consensus forming between all parties on the creation of community energy systems.

\section{Appendix}

See Figs. 1, 2, 3 and 4 


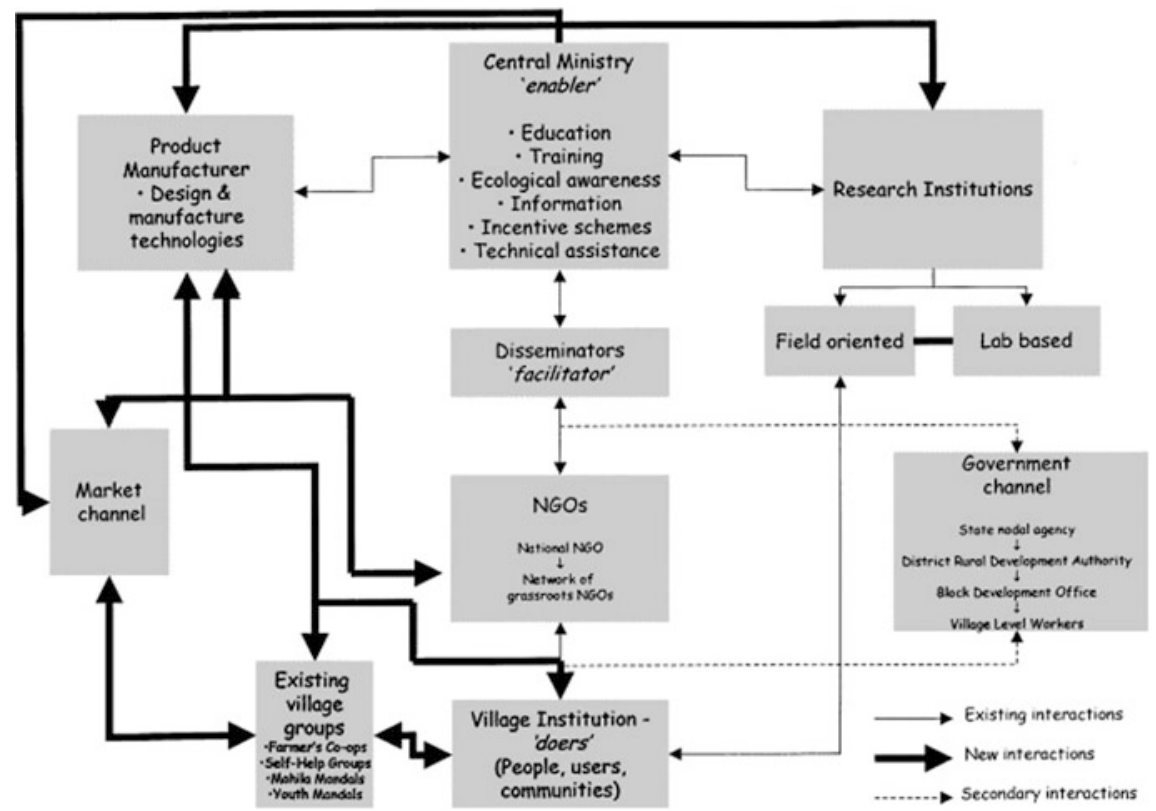

Fig. 1 Model for new stakeholder roles in rural energy planning in India (Neudoerffer 2001)

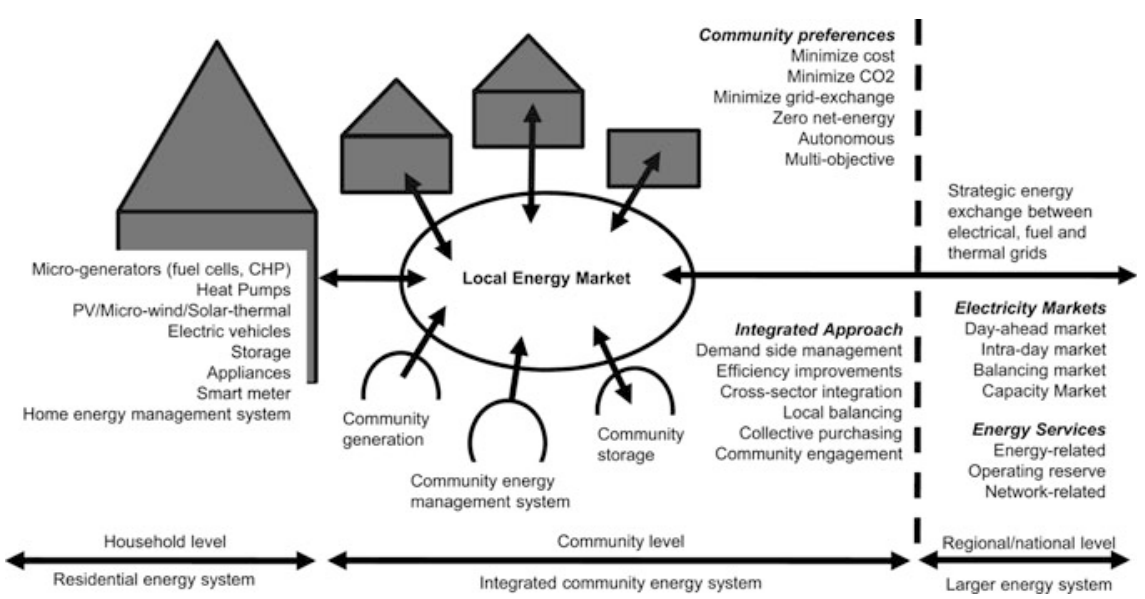

Fig. 2 Functions of an integrated community energy system (ICES) in the larger system (Koirala et al. 2016) 


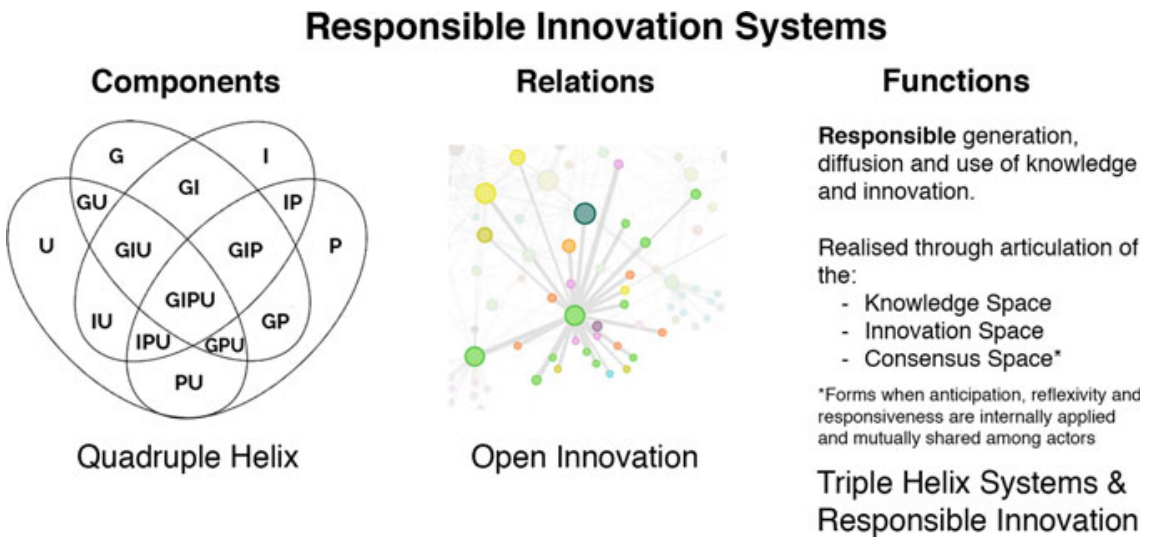

Fig. 3 A synthetic representation of the Responsible Innovation Systems framework, with G, I, P \& $\mathrm{U}$, respectively, indicating government, industry, public (civil society) and university (academia) [10]

Fig. 4 Proposed institutional division of stakeholders for the initial phase co-creation processes of ICESs, with each line depicting a potential interaction for later phases. Preferably, local, national and international stakeholders should be included

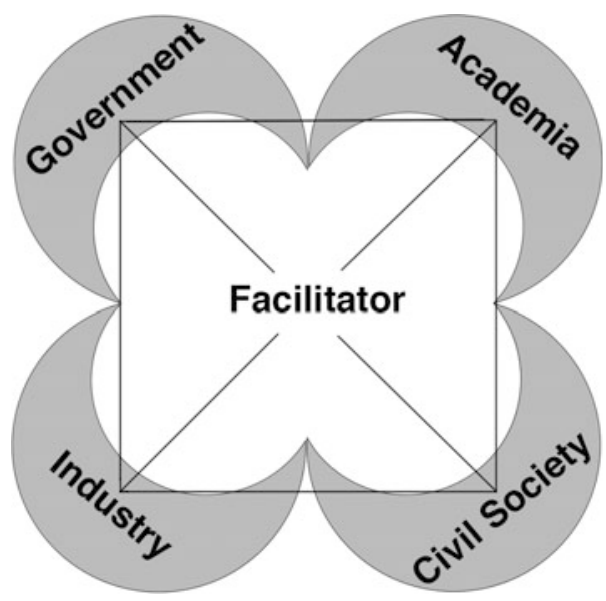

\section{References}

1. Banerjee AV, Banerji R, Duflo E, Glennerster R, Khemani S (2010) Pitfalls of participatory programs: Evidence from a randomized evaluation in education in India. Am Econ J: Econ Policy 2(1): $1-30$

2. Carayannis EG, Campbell DF (2009) 'Mode 3' and 'quadruple helix': toward a 21st century fractal innovation ecosystem. Int J Technol Manage 46(3-4):201-234

3. CEEW (2015) Access to clean cooking energy and electricity. Technical report

4. Chesbrough HW (2006) Open innovation: the new imperative for creating and profiting from technology. Harvard Business Press

5. Comello SD, Reichelstein SJ, Sahoo A, Schmidt TS (2017) Enabling mini-grid development in rural india. World Dev 93:94-107 
6. Devine-Wright P, Batel S, Aas O, Sovacool B, Labelle M, Ruud A (2017) A conceptual framework for understanding the social acceptance of energy infrastructure: Insights from energy storage. Energy Policy 107:27-31. https://doi.org/10.1016/j.enpol.2017.04.020

7. Fernández-Baldor Á, Lillo P, Boni A (2015) Gender, energy, and inequalities: a capabilities approach analysis of renewable electrification projects in Peru. In: Sustainable access to energy in the global south. Springer, Cham, pp 193-204

8. Haggett C, Aitken M (2015) Grassroots energy innovations: the role of community ownership and investment. Curr Sustain/Renew Energy Rep 2(3):98-104

9. Haggett C, Creamer E, Harnmeijer J, Parsons M, Bomberg E (2013) Community energy in Scotland: the social factors for success. University of Edinburgh, Edinburgh

10. Hunink YTA, Kamp LM, Blom E (2018) Developing responsible innovation systems: the case of the rural energy sector in India. Working paper awaiting publication

11. International Energy Agency (2017) World energy outlook 2017 data on energy access. Retrieved on 04-12-17 from: http://www.iea.org/

12. Joshi A, Witcombe JR (1996) Farmer participatory crop improvement. II. Participatory varietal selection, a case study in India. Exp Agric 32(4):461-477

13. Oteman M, Wiering M, Helderman JK (2014) The institutional space of community initiatives for renewable energy: a comparative case study of the Netherlands, Germany and Denmark. Energy Sustain Soc 4(1):11

14. Palit D, Chaurey A (2011) Off-grid rural electrification experiences from South Asia: status and best practices. Energy Sustain Dev 15(3):266-276

15. Parag Y, Janda KB (2014) More than filler: Middle actors and socio-technical change in the energy system from the "middle-out". Energy Res Soc Sci 3:102-112

16. Ranga M, Etzkowitz H (2013) Triple helix systems: an analytical framework for innovation policy and practice in the knowledge society. Ind High Educ 27(4):237-262

17. Ravindra K, Kannan B, Ramappa N (2014) Microgrids: a value-based paradigm: the need for the redefinition of microgrids. IEEE Electrification Magazine 2(1):20-29

18. Siddiqui FA (2003) Linking innovation and local uptake in rural development: potential for renewable energy cooperatives in Bangladesh (Doctoral dissertation, Murdoch University)

19. Singh A, Strating AT, Herrera NR, van Dijk HW, Keyson DV (2017) Towards an ethnography of electrification in rural India: Social relations and values in household energy exchanges. Energy Res Soc Sci 30:103-115

20. Smallridge CG (1999) Rural energy and development: a study of canadian rural electrification. CG Smallridge \& Associates, Ottawa, Canada

21. Stilgoe J, Owen R, Macnaghten P (2013) Developing a framework for responsible innovation. Res Policy 42(9):1568-1580

22. Viardot $\mathrm{E}$ (2013) The role of cooperatives in overcoming the barriers to adoption of renewable energy. Energy Policy 63:756-764

23. Wüstenhagen R, Wolsink M, Bürer MJ (2007) Social acceptance of renewable energy innovation: an introduction to the concept. Energy Policy 35:2683-2691 